\title{
Defective angles of localized retinal nerve fiber layer reflect the severity of visual field defect- a cross-sectional analysis
}

\author{
Alexander Chen ${ }^{1 \dagger}$, Ing-Chou Lai ${ }^{1,2+}$, Wan-Hua Cho ${ }^{1}$, Hung-Yin Lai ${ }^{1}$, Pei-Wen Lin ${ }^{1,2}$, Pei-Chang Wu ${ }^{1,2}$ and \\ Ming-Tse Kuo ${ }^{1,2^{*}}$
}

\begin{abstract}
Background: In order to detect glaucomatous optic nerve damages early on and evaluate the severity of glaucoma, a previously developed analytic method based on photographic retinal nerve fiber layer (RNFL) angle defect was proposed. However, the correlation between these defective angles and the severity of visual field defect has not been verified. This study aimed to confirm the correlation described above.

Methods: We reviewed a total of 227 glaucomatous eyes (38 enrolled, 189 excluded) during an interval of 5 years. The angles of all eyes were measured on RNFL photograph, of which angle $a$ is the angular width between the macula center and the proximity of RNFL defect, and angle $\beta(+c)$ is the sum of angular width(s) of localized RNFL defect. The severity of visual field defect was determined by mean deviation (MD), pattern standard deviation (PSD), and visual field index (VFI). Correlation analysis was performed on angle $a$ and angle $\beta(+c)$ with the presence of central scotoma and visual field defect parameters, respectively.
\end{abstract}

Results: Angle $\beta(+C)$ showed significant correlation with MD $(P=0.007)$, PSD $(P=0.02)$, VFI $(P=0.03)$, and average RNFL thickness $(P=0.03)$. No correlation was found between angle $a$ and the presence of central scotoma.

Conclusions: In conclusion, measuring the angular width of localized RNFL defect is a viable method for determining the severity of visual field defect.

Keywords: Localized retinal nerve fiber layer, Visual field defect parameters, Fundus photograph

\section{Background}

Glaucoma is globally ranked the second most common cause of blindness [1]. Early detection is of utmost importance for glaucomatous eyes, and using conventional retinal nerve fiber layer (RNFL) photograph to evaluate localized retinal nerve fiber layer defects (RNLFD) is a tool of choice for detecting early glaucomatous eyes when optical coherence topography (OCT) is unavailable.

\footnotetext{
* Correspondence: mingtse@cgmh.org.tw

${ }^{+}$Alexander Chen and Ing-Chou Lai contributed equally to this work. 'Department of Ophthalmology, Kaohsiung Chang Gung Memorial Hospital and Chang Gung University College of Medicine, Kaohsiung 83301, Taiwan ${ }^{2}$ Chang Gung University College of Medicine, Taoyuan 333, Taiwan
}

However, there is a lack of established quantitative analysis using RNFL photograph.

Woo et al. previously established a convenient quantitative method for analyzing localized RNFL defect using RNFL photograph by measuring the angles around the disc [2]. They first defined the reference line as the line between the macula center and the optic disc center. Angle $\alpha$ is the angular width between the reference line and the proximity of RNFL defect, while angle $\beta(+\mathrm{c})$ is the sum of angular width(s) of localized RNFL defect. This method was then used to compare different etiologies of various types of glaucoma [2,3]. The idea was built upon the assumption that localized RNFLD or the

C C The Author(s). 2020 Open Access This article is licensed under a Creative Commons Attribution 4.0 International License, which permits use, sharing, adaptation, distribution and reproduction in any medium or format, as long as you give appropriate credit to the original author(s) and the source, provide a link to the Creative Commons licence, and indicate if changes were made. The images or other third party material in this article are included in the article's Creative Commons licence, unless indicated otherwise in a credit line to the material. If material is not included in the article's Creative Commons licence and your intended use is not permitted by statutory regulation or exceeds the permitted use, you will need to obtain permission directly from the copyright holder. To view a copy of this licence, visit http://creativecommons.org/licenses/by/4.0/ The Creative Commons Public Domain Dedication waiver (http://creativecommons.org/publicdomain/zero/1.0/) applies to the data made available in this article, unless otherwise stated in a credit line to the data. 
optic nerve head configuration [4-7] is somehow correlated with the visual field defect, but the validity of such correlation has not been verified.

There are several implications in validating such quantitative method. Firstly, if the sum of the angular width of the localized RNFL defect, or angle $\beta(+c)$, is indeed correlated with visual field defect, the severity of visual field defect can be predicted by the morphological defect of localized RNFL. Secondly, if the angular width between the reference line and the proximity of RNFL defect, or angle $\alpha$, is correlated with central scotoma, we may use this as an indicator for earlier or more aggressive treatment [8] since central visual field defect drastically affects patient's life quality [9]. In fact, patients with central visual field defect are associated with reading difficulty [10], worsening of driving performance [11], and are at greater risk of visual acuity loss [12]. The verified method can possibly be adopted as a new parameter in optical coherence tomography (OCT). Moreover, this method can be popularly implemented in local clinics and developing countries without OCT.

Thus, this study aims to confirm the correlation between the localized RNFL angle defect and the visual field defect.

\section{Methods}

\section{Participant recruitment}

This study was approved by the Institutional Review Board of Chang Gung Memorial Hospital, Kaohsiung, Taiwan (Registration Number: 201701398B0) and adhered to the tenets of the Declaration of Helsinki. A retrospective single-center cross-sectional study of glaucomatous eyes was conducted. The clinical records of 227 glaucomatous eyes (38 enrolled, 189 excluded) diagnosed at the glaucoma clinic of Chang Gung Memorial Hospital during an interval of 5 years were carefully reviewed and were anonymized before analysis (Fig. 1).

All patients underwent complete ophthalmological evaluations including Snellen visual acuity measurements, gonioscopy, pneuma-tonometry, dilated fundus examination of the optic disc with a 90-diopter lens (Volk super 666, Volk Optical Inc., Mentor, Ohio, USA), RNFL photography (Topcon retinal camera TRC-50EX, Itabashiku, Tokyo, Japan), and visual field test with Humphrey field analyzer (30-2 Program, Carl Zeiss Meditec, Inc., Dublin, CA, USA). Average RNFL thickness was obtained from spectral domain optical coherence tomography (Spectralis OCT, Heidelberg Engineering, Heidelberg, Germany) for comparison since previous studies have reported correlation between visual field defect and average RNFL thickness [13-15].

Glaucomatous eyes were defined using the AndersonPatella's criteria. Visual field defects had to be compatible with RNFL defects and repeatable on at least two consecutive tests. The exclusion criteria included those with previous ophthalmic abnormalities such as retinal diseases, uveitis, previous ocular surgeries, best-corrected visual acuity $(B C V A)<20 / 50$, as well as cases that were difficult to identify RNFL defects due to poor quality of RNFL photograph (Fig. 1).

\section{Visual field defect parameters}

The parameters of visual field defect severity were determined by visual field mean deviation (MD), visual field pattern standard deviation (PSD), and visual field index (VFI). No previous studies defined central scotoma with $30-2$ visual field test, so we proposed the following criteria to define central scotoma: two or more points with $<5 \%$ and/or one or more points with $<2 \%$ within the central 6 degrees of fixation. In order to reinforce the reliability of our visual field parameters, we excluded those with fixation losses $>20 \%$ [16], false positive errors $>10 \%$, false negative errors $>15 \%$, and visual field $\mathrm{MD}<-14 \mathrm{~dB}$ (Fig. 1).

\section{Localized retinal nerve fiber layer defect parameters}

Localized RNFL defect was defined as wedge-shaped nonspindle-like defects touching or running towards the optic disc border [17]. The method [2] of angle measurements for evaluating localized RNFL defect was as follows (Fig. 2):

\section{Reference line $=$ the line between the macula center and the optic disc center}

1. Angle $\alpha=$ the angular width between the reference line and the proximity of RNFL defect.

2. Angle $\beta(+\mathrm{c})=$ the sum of angular width $(\mathrm{s})$ of localized RNFL defect.

Those with localized RNFL defects greater than 120 degrees from the reference line were excluded since the nasal RNFL defects were hard to determine. The average degrees of defective angles in RNFL photographs, of which patients' medical record information were blinded, were measured using ImageJ software (version 1.51j8, developed by Wayne Rasband, National Institutes of Health, Bethesda, MD, USA http://imagej.nih.gov/ij) by three ophthalmologists. We performed an analysis on inter-rater reliability using SPSS to evaluate the absolute agreement between the raters and found that the correlation of the average measures of angle $\alpha$ and angle $\beta(+\mathrm{c})$ among the three raters was 0.998 (95\% confidence interval 0.996-0.999) and 0.996 (95\% confidence interval 0.992-0.998), suggesting very strong correlations among the three raters.

Correlation analysis was then performed on angle $\alpha$ and angle $\beta(+\mathrm{c})$ with the presence of central scotoma and visual field defect parameters, respectively.

\section{Sample size determination}

Using a free power calculator (http://powerandsamplesize. $\mathrm{com} /$ Calculators/Validations), the sample size of at least 


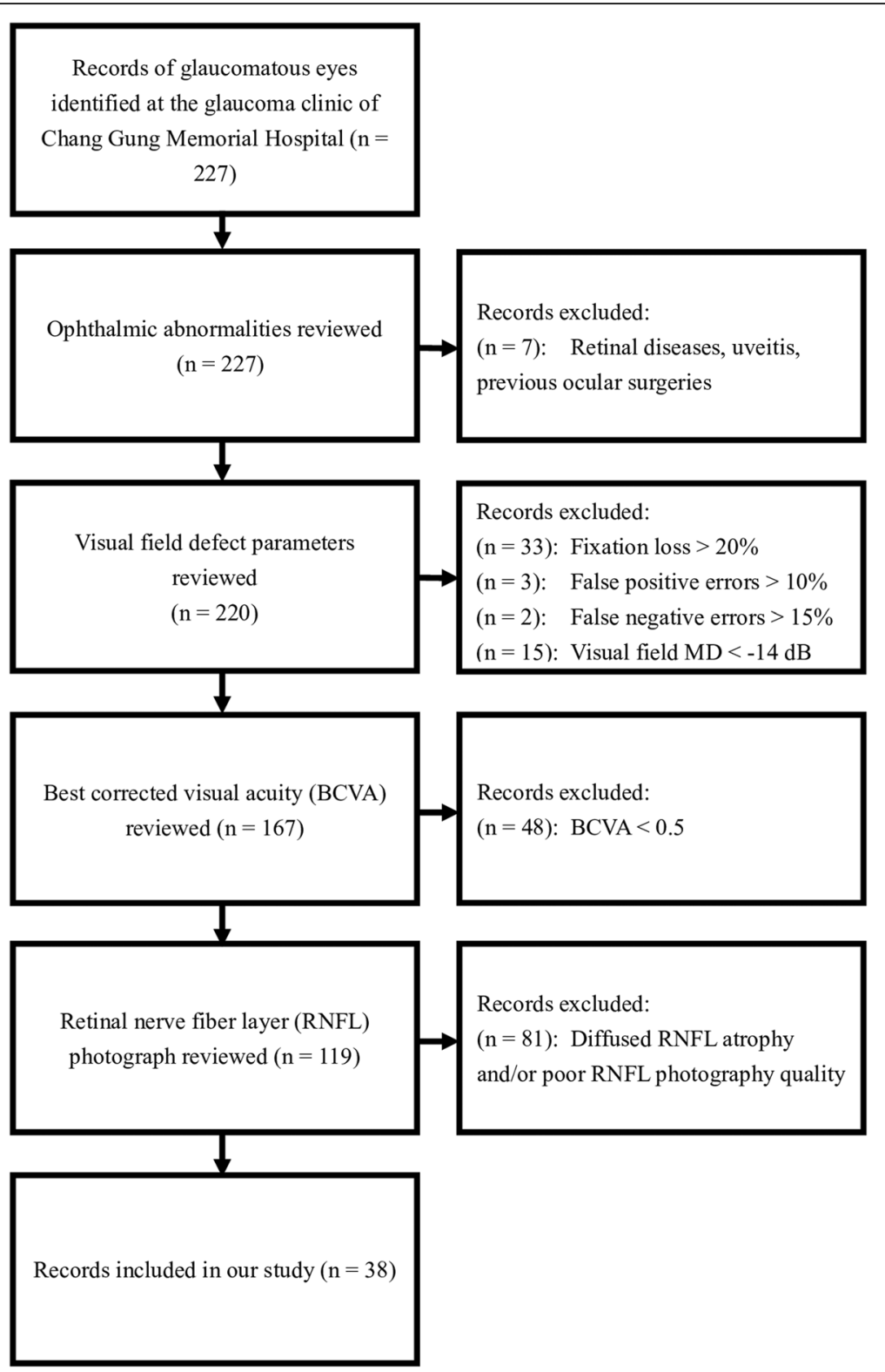

Fig. 1 Inclusion and exclusion flowchart. A total of 227 clinical records were reviewed. After scrupulous screening using the above exclusion criteria, 38 eyes were included into our study

37 eyes was estimated based on the mean differences of angle $\alpha$ and angle $\beta(+c)$ per $1 \mathrm{~dB}$ change of MD between high and low myopia patients according to Kim et al. under the power of 0.90 [3].

\section{Statistical analysis}

All statistical analyses were performed using SPSS software (version 12.0; SPSS Inc., Chicago, IL, USA). Data were presented in the forms of means \pm standard deviation or frequencies unless otherwise specified. A $P$ value $<0.05$ was considered as statistically significant. Spearman's rank correlation test was used to analyze the association of angle $\alpha$ and the presence of central scotoma as well as angle $\beta(+\mathrm{c})$ and visual field defect parameters. Inter-rater reliability was performed using two-way mixed and absolute agreement settings.

\section{Results}

A total of 38 glaucomatous eyes of 227 patients were enrolled for this cross-sectional analysis with the mean age of $59.0 \pm 8.8$ years. Baseline characteristics were listed in Table 1. Participants were of early glaucoma defects with an average visual field $\mathrm{MD}$ of $-4.7 \pm 3.2 \mathrm{~dB}$ and an average RNFL thickness of $76.1 \pm 16.3 \mu \mathrm{m}$. The mean of angle $\alpha$ and angle $\beta(+c)$ was $41.1 \pm 17.2$ and $53.8 \pm 20.4$. Spearman's rank correlation test was used to analyze the 

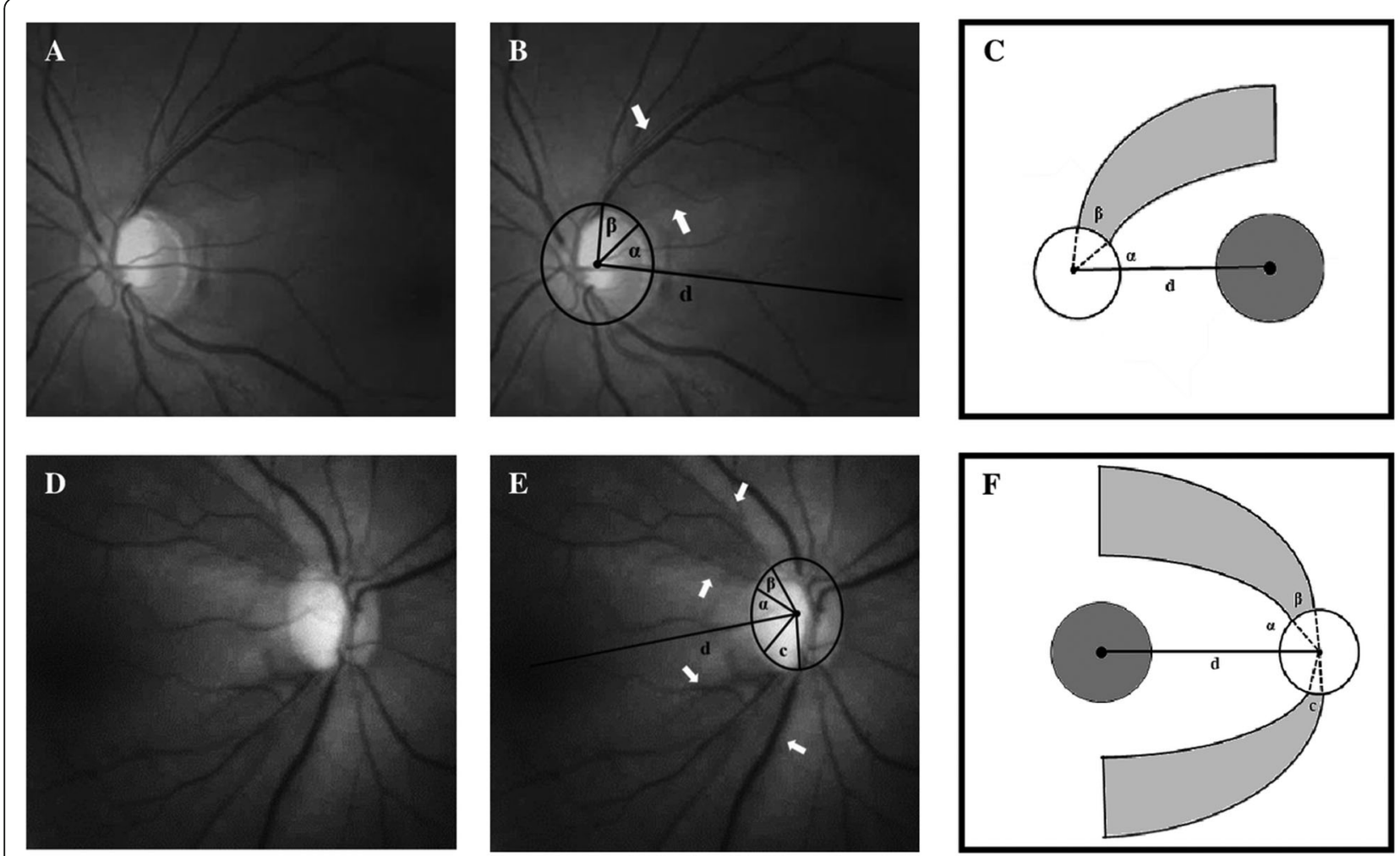

Fig. 2 Parameters of localized retinal nerve fiber layer (RNFL) defect were identified using RNFL photography. a Localized RNFL defect of a left eye without labeling. b Localized RNFL defect with labeled parameters. c Schematic illustration of (b). $\mathbf{d}$ Localized RNFL defect of a right eye without labeling. e Localized RNFL defect with labeled parameters. $\mathbf{f}$ Schematic illustration of (e). Localized RNFL defect is defined with the white arrows. Reference line $d$ is the line between the macula center and the optic disc center. Angle $a$ is the angular width between the reference line and the proximity of the RNFL defect. Angle $\beta(+c)$ is the sum of angular width(s) of localized RNFL defect

correlation of angle $\alpha$ with the presence of central scotoma $(P=0.82)$ and average total macular thickness $(P=0.21)$ and no correlations were found. In Table 2 , angle $\beta(+\mathrm{c})$ was significantly correlated with $\mathrm{MD}(P=0.007), \operatorname{PSD}(P=$ $0.02)$, VFI $(P=0.03)$, and average RNFL thickness $(P=$ $0.03)$.

As for the angular measurements of RNLFD relative to the sectoral RNFL thickness, Spearman's rank correlation test was used to analyze their correlation and found that they were negative correlated significantly $(P=0.01)$. Further analysis on the correlation between OCT sectoral RNFL defect and the severity of visual field defect (Table 3) showed no significant correlation with MD $(P=0.34)$, PSD $(P=0.41)$, and VFI $(P=0.14)$. We then analyzed the correlation of global (average) RNFL thickness with the visual field parameters (Table 2) and found that average RNFL thickness was significantly correlated with MD $(P=$ $0.000)$, PSD $(P=0.003)$, and VFI $(P=0.001)$.

\section{Discussion}

In this study, we found that the extent of localized RNFL angle defect is positively correlated with the visual field defect. This method not only benefits countries where
OCTs are not available but also has the potential to be implemented as a new parameter for OCT in developed countries.

Several studies have already shown that RNFL thickness can be noticed earlier than visual field defect during early stages of glaucoma $[18,19]$. The correlation between the structural damage of RNFL thickness and functional damage of the visual field has also been identified in multiple studies [13, 20-22]. In addition, Sommer et al. previously identified a $60 \%$ rate of structural RNFL abnormality 5 years before visual field loss, which suggested RNFL defect as a very early indicator of glaucoma [23]. The above evidences acknowledged the diagnostic value of structural RNFL abnormalities in early glaucoma, but unlike RNLF thickness, localized RNFL defect lacks a method of quantitative analysis. In this study, we showed that the measurement of RNFL angle defect around the disc proposed by Woo et al. [2] is an effective way to estimate the severity of visual field defect. It is also worth mentioning that the strength of our study depends on the reliability of visual field defect parameters after screening with the strict exclusion criteria we have imposed. 
Table 1 Baseline characteristics of the participants

\begin{tabular}{ll}
\hline & Glaucomatous eye \\
\hline Right eyes & $17(44.7)$ \\
Age (yr) & $59.0(8.8)$ \\
Male & $22(57.9)$ \\
Spherical Equivalence (D) & $-0.5(2.6)$ \\
Angle a (degrees) & $41.1(17.2)$ \\
Angle $\beta+c$ (degrees) & $53.8(20.4)$ \\
Intraocular Pressure (mmHg) & $14.8(4.1)$ \\
Humphrey field analyzer 30-2 & \\
Visual Field Index (\%) & $90.0(9.8)$ \\
Fixation Losses & $5.7(6.2)$ \\
False Positive Errors (\%) & $1.4(1.7)$ \\
False Negative Errors (\%) & $2.1(2.9)$ \\
Visual Field MD (dB) & $-4.7(3.2)$ \\
Visual Field PSD (dB) & $6.1(4.4)$ \\
Presence of Central Scotoma & $26(68.4)$ \\
Spectralis optical coherence tomography & \\
Average RNFL Thickness ( $\mu$ m) & $76.1(16.3)$ \\
Average total macular thickness ( $\mu$ m) & $269.3(16.4)$ \\
\hline Values are expressed as number (frequency) or average (standard deviation) \\
MD mean deviation, PSD pattern standard deviation, RNFL retinal nerve fiber layer
\end{tabular}

In regard to angle $\alpha$, we did not find significant correlation with the presence of central scotoma. Recall that angle $\alpha$ is the angular width between the reference line and the proximity of RNFL defect. Hence, it makes sense that the smaller the angle $\alpha$, the closer the RNFL defect is relative to the central vision and cause central visual defect. We proposed four possible explanations for the lack of correlation. Firstly, some studies suggested that RNFL thickness loss is significantly correlated with more circumferential visual field loss but is not correlated with the central visual field loss [24, 25]. Secondly, early glaucomatous optic nerve damages precede visual loss most of the time [23, 26]. Thirdly, the presence of central scotoma was identified based on $30-2$ visual fields using the criteria we proposed instead of using 10 2 visual fields, of which we lack. This deficit in accurately defining central scotoma may have caused the lack of correlation. Fourthly, from a physiological standpoint,
Table 3 Correlation among visual field defect parameters, localized retinal nerve fiber layer defect angle $\beta(+c)$, sectoral, and average retinal nerve fiber layer thickness

\begin{tabular}{lllll}
\hline & Correlation & MD & PSD & VFI \\
\hline Sectoral & $\mathrm{R}$ & 0.161 & -0.136 & 0.245 \\
RNFLT & $P$ & 0.34 & 0.41 & 0.14 \\
Average & $\mathrm{R}$ & $\mathbf{0 . 6 5 9}$ & $\mathbf{- 0 . 4 6 9}$ & $\mathbf{0 . 5 1 0}$ \\
RNFLT & $P$ & $\mathbf{0 . 0 0 0}$ & $\mathbf{0 . 0 0 3}$ & $\mathbf{0 . 0 0 1}$
\end{tabular}

$M D$ mean deviation of visual field, $P S D$ pattern standard deviation of visual field, VFI visual field index, RNFLT retinal nerve fiber layer thickness, $P P$ value, $R$ Spearman's correlation coefficient

Spearman's rank correlation was performed

Correlations significant at $\boldsymbol{P}<\mathbf{0 . 0 5}$ are bolded

central RNFL lesion is closer to the origin of retinal vessels and may thereby receive more nutritional support, stronger cellular reinforcements, and thus develop more visual field compensation as compared to peripheral RNFL. Altogether, we believe that there may be correlation between angle $\alpha$ and the presence of central scotoma, but the timing of ocular examination and the definition of central scotoma may have concealed the underlying correlation in this study.

We further evaluated whether our method is comparable to that of the OCT in reflecting the severity of visual field defect through Spearman's rank correlation test. Sectoral RNFL thickness of the OCT, which were adjusted whether it was superior temporal, inferior temporal, or combined accordingly to the RNFL defect, showed no significant correlation with visual field parameters. This suggested that our method has noninferior correlation with visual field parameters as compared to that of the OCT's sectoral RNFL thickness. We then analyzed the correlation of global (average) RNFL thickness with the visual field parameters for the purpose of positive control and found that average RNFL thickness was significantly correlated with the visual field parameters. This suggested that in regard to the correlation with visual field parameters, our method is noninferior to OCT's sectoral RNFL thickness and slightly inferior to the average RNFL thickness. All in all, the angular measurement of RNFLD via RNFL photograph is comparable to the average RNFL thickness of the OCT in reflecting the severity of visual field defect.

Table 2 Correlation between localized retinal nerve fiber layer defect angle $\beta(+c)$ and visual field defect parameters, and average retinal nerve fiber layer thickness

\begin{tabular}{|c|c|c|c|c|c|}
\hline & Correlation & MD & PSD & VFI & Average RNFLT \\
\hline \multirow[t]{2}{*}{ Angle $\beta+c$} & R $(95 \%$ Cl) & $-0.428(-1.17-0.73)$ & $0.366(-0.45-1.39)$ & $-0.364(-0.79-1.69)$ & $-0.350(-0.65-0.216)$ \\
\hline & $P$ & 0.007 & 0.02 & 0.03 & 0.03 \\
\hline
\end{tabular}

Cl confidence interval, MD mean deviation of visual field, $P S D$ pattern standard deviation of visual field, VFI visual field index, $R N F L T$ retinal nerve fiber layer thickness, $P P$ value, $R$ Spearman's correlation coefficient

Spearman's rank correlation was performed

Correlations significant at $\boldsymbol{P}<\mathbf{0 . 0 5}$ are bolded 
There were some limitations in our study. First, the subjectivity of angle measurements using Image J software limits the applicability, but this technique may be valuable if it is encompassed as one of the parameters of the OCT in the future. Second, inclusion rate is low due to high RNFL photography quality requirements. Third, the data of our participants were collected from a single medical center, which results in selection bias. Fourth, the results of visual field tests in this study were all based on 30-2 visual fields. Thus, minor visual field defects may be present under 10-2 visual fields that were undetectable via 30-2 visual fields. Fourth, diabetes and hypertension may be related to RNFLD, but we did not particularly exclude the above systemic diseases since we only seek to identify the correlation of the parameters.

\section{Conclusion}

In summary, our study suggested that the quantification of localized RNFL defects is potentially useful for glaucoma diagnosis and that the width of RNFL defects was correlated to visual field indices in early stages of glaucoma.

\section{Abbreviations}

BCVA: best-corrected visual acuity; MD: mean deviation; OCT: optical coherence tomography; PSD: pattern standard deviation; RNFL: retinal nerve fiber layer; VFI: visual field index

\section{Acknowledgements}

The authors are indebted to technicians and research assistants of the retina team.

\section{Authors' contributions}

$A C, M K$, and IL conceived and designed the analysis. AC and MK were the major contributors in writing the manuscript. WC, and $\mathrm{HL}$ conducted the analysis and interpreted the data regarding the correlation of defective angles of the localized RNFL and the visual field defect parameters. PL and $\mathrm{PW}$ revised the manuscript and contributed significantly in the discussion section. All authors have read and approved the manuscript.

\section{Funding}

None.

\section{Availability of data and materials}

The datasets analysed during the current study are available upon reasonable request.

\section{Ethics approval and consent to participate}

This study was approved by the Institutional Review Board of Chang Gung Memorial Hospital, Kaohsiung, Taiwan (Registration Number: 201701398B0) and adhered to the tenets of the Declaration of Helsinki.

\section{Consent for publication}

Not applicable. This was a retrospective study, of which only clinical records of the participants were reviewed and were anonymized before the analysis.

\section{Competing interests}

The authors declare that there is no competing interest regarding the publication of this article.

Received: 30 March 2019 Accepted: 20 March 2020

Published online: 09 April 2020

\section{References}

1. Kingman S. Glaucoma is second leading cause of blindness globally. Bull World Health Organ. 2004;82(11):887-8.
2. Woo SJ, Park KH, Kim DM. Comparison of localised nerve fibre layer defects in normal tension glaucoma and primary open angle glaucoma. $\mathrm{Br} J$ Ophthalmol. 2003;87(6):695-8.

3. Kim JM, Park KH, Kim SJ, Jang HJ, Noh E, Kim MJ, et al. Comparison of localized retinal nerve fiber layer defects in highly myopic, myopic, and non-myopic patients with normal-tension glaucoma: a retrospective crosssectional study. BMC Ophthalmol. 2013;13:67.

4. Caprioli J, Spaeth GL. Comparison of the optic nerve head in high- and lowtension glaucoma. Arch Ophthalmol. 1985;103(8):1145-9.

5. Miller KM, Quigley HA. Comparison of optic disc features in low-tension and typical open-angle glaucoma. Ophthalmic Surg. 1987;18(12):882-9.

6. Fazio P, Krupin T, Feitl ME, Werner EB, Carre DA. Optic disc topography in patients with low-tension and primary open angle glaucoma. Arch Ophthalmol. 1990;108(5):705-8.

7. Yamagami J, Araie M, Shirato S. A comparative study of optic nerve head in low- and high-tension glaucomas. Graefes Arch Clin Exp Ophthalmol. 1992; 230(5):446-50.

8. Membrey WL, Poinoosawmy DP, Bunce C, Fitzke FW, Hitchings RA. Comparison of visual field progression in patients with normal pressure glaucoma between eyes with and without visual field loss that threatens fixation. Br J Ophthalmol. 2000;84(10):1154-8.

9. Goldberg I, Clement Cl, Chiang TH, Walt JG, Lee LJ, Graham S, et al. Assessing quality of life in patients with glaucoma using the glaucoma quality of life-15 (GQL-15) questionnaire. J Glaucoma. 2009;18(1):6-12.

10. Kanonidou E. Reading performance and central field loss. Hippokratia. 2011; 15(2):103-8

11. Bronstad PM, Albu A, Goldstein R, Peli E, Bowers AR. Driving with central field loss III: vehicle control. Clin Exp Optom. 2016;99(5):435-40.

12. Kolker AE. Visual prognosis in advanced glaucoma: a comparison of medical and surgical therapy for retention of vision in 101 eyes with advanced glaucoma. Trans Am Ophthalmol Soc. 1977;75:539-55.

13. Alasil T, Wang K, Yu F, Field MG, Lee H, Baniasadi N, et al. Correlation of retinal nerve fiber layer thickness and visual fields in glaucoma: a broken stick model. Am J Ophthalmol. 2014;157(5):953-9.

14. Tenkumo K, Hirooka K, Baba T, Nitta E, Sato S, Shiraga F. Evaluation of relationship between retinal nerve fiber layer thickness progression and visual field progression in patients with glaucoma. Jpn J Ophthalmol. 2013; 57(5):451-6.

15. Suh W, Lee JM, Kee C. Depth and area of retinal nerve fiber layer damage and visual field correlation analysis. Korean J Ophthalmol. 2014;28(4):323-9.

16. Birt CM, Shin DH, Samudrala V, Hughes BA, Kim C, Lee D. Analysis of reliability indices from Humphrey visual field tests in an urban glaucoma population. Ophthalmology. 1997;104(7):1126-30.

17. Sugiyama K, Uchida H, Tomita G, Sato Y, Iwase A, Kitazawa Y. Localized wedge-shaped defects of retinal nerve fiber layer and disc hemorrhage in glaucoma. Ophthalmology. 1999;106(9):1762-7.

18. Leung CK, Medeiros FA, Zangwill LM, Sample PA, Bowd C, Ng D, et al. American Chinese glaucoma imaging study: a comparison of the optic disc and retinal nerve fiber layer in detecting glaucomatous damage. Invest Ophthalmol Vis Sci. 2007:48(6):2644-52.

19. Schlottmann PG, De Cilla S, Greenfield DS, Caprioli J, Garway-Heath DF. Relationship between visual field sensitivity and retinal nerve fiber layer thickness as measured by scanning laser polarimetry. Invest Ophthalmol Vis Sci. 2004;45(6):1823-9.

20. Garway-Heath DF, Poinoosawmy D, Fitzke FW, Hitchings RA. Mapping the visual field to the optic disc in normal tension glaucoma eyes. Ophthalmology. 2000;107(10):1809-15.

21. Hood DC, Anderson SC, Wall M, Raza AS, Kardon RH. A test of a linear model of glaucomatous structure-function loss reveals sources of variability in retinal nerve fiber and visual field measurements. Invest Ophthalmol Vis Sci. 2009:50(9):4254-66.

22. Malik R, Swanson WH, Garway-Heath DF. 'Structure-function relationship' in glaucoma: past thinking and current concepts. Clin Exp Ophthalmol. 2012; 40(4):369-80.

23. Sommer A, Katz J, Quigley HA, Miller NR, Robin AL, Richter RC, et al. Clinically detectable nerve fiber atrophy precedes the onset of glaucomatous field loss. Arch Ophthalmol. 1991;109(1):77-83.

24. Horn FK, Mardin CY, Laemmer R, Baleanu D, Juenemann AM, Kruse FE, et al. Correlation between local glaucomatous visual field defects and loss of nerve fiber layer thickness measured with polarimetry and spectral domain OCT. Invest Ophthalmol Vis Sci. 2009;50(5):1971-7. 
25. Horn FK, Mardin CY, Viestenz A, Junemann AG. Association between localized visual field losses and thickness deviation of the nerve fiber layer in glaucoma. J Glaucoma. 2005;14(6):419-25.

26. Kanamori A, Nakamura M, Escano MF, Seya R, Maeda H, Negi A. Evaluation of the glaucomatous damage on retinal nerve fiber layer thickness measured by optical coherence tomography. Am J Ophthalmol. 2003;135(4): $513-20$

\section{Publisher's Note}

Springer Nature remains neutral with regard to jurisdictional claims in published maps and institutional affiliations.

Ready to submit your research? Choose BMC and benefit from:

- fast, convenient online submission

- thorough peer review by experienced researchers in your field

- rapid publication on acceptance

- support for research data, including large and complex data types

- gold Open Access which fosters wider collaboration and increased citations

- maximum visibility for your research: over $100 \mathrm{M}$ website views per year

At $\mathrm{BMC}$, research is always in progress.

Learn more biomedcentral.com/submissions 